\title{
Interferon $\gamma$ suppresses dentin sialophosphoprotein in oral squamous cell carcinoma cells resulting in antitumor effects, via modulation of the endoplasmic reticulum response
}

\author{
IOANNIS GKOUVERIS ${ }^{1}$, NIKOLAOS G. NIKITAKIS ${ }^{2}$, JAYA ASSERVATHAM ${ }^{3}$ and KALU U.E. OGBUREKE ${ }^{3}$ \\ ${ }^{1}$ Division of Diagnostic and Surgical Sciences, UCLA School of Dentistry, Los Angeles, CA 90095, USA; \\ ${ }^{2}$ Department of Oral Medicine and Pathology, School of Dentistry, National and Kapodistrian University of Athens, \\ Athens 11527, Greece; ${ }^{3}$ Department of Diagnostic and Biomedical Sciences, School of Dentistry, \\ University of Texas Health Science Center at Houston, Houston, TX 77054, USA
}

Received May 17, 2018; Accepted September 19, 2018

DOI: 10.3892/ijo.2018.4590

\begin{abstract}
The expression of proinflammatory cytokines in various malignant neoplasms is widely considered to represent the host immune response to tumor development. The role of interferon (IFN) $\gamma$ in head and neck squamous cell carcinoma, and its association with endoplasmic reticulum (ER) stress pathways, remains a subject of ongoing investigation. Dentin sialophosphoprotein (DSPP), which is a member of the small integrin-binding N-linked glycoproteins family, has been implicated in malignant transformation and invasion of oral squamous cell carcinoma (OSCC). Recent studies have established matrix metalloproteinase (MMP)20 as the cognate MMP partner of DSPP. The present study examined the effects of IFN $\gamma$ treatment on DSPP and MMP20 expression, ER stress, the unfolded protein response (UPR), and calcium $(\mathrm{Ca})$ homeostasis regulatory mechanisms in OSCC cells. The OSC2 OSCC cell line was treated with IFN $\gamma$ at specific time-points. At each time-point, the mRNA expression levels of DSPP and MMP20, and those of ER-stress-, UPR- and $\mathrm{Ca}$ homeostasis-associated proteins [78-kDa glucose-regulated protein (GRP78), sarco/endoplasmic reticulum $\mathrm{Ca}^{2+}$-ATPase (SERCA2b), inositol 1,4,5-trisphosphate receptor (IP3r), protein kinase R-like ER kinase (PERK) and inositol-requiring enzyme 1 (IRE1)], were assessed by reverse transcription-quantitative polymerase chain reaction. The protein expression levels of B-cell lymphoma 2 (Bcl-2), Bcl-2-associated $\mathrm{X}$ protein (Bax), proliferating cell nuclear antigen (PCNA) and cytochrome $c$ were analyzed by western
\end{abstract}

Correspondence to: Professor Kalu U.E. Ogbureke, Department of Diagnostic and Biomedical Sciences, School of Dentistry, University of Texas Health Sciences Center at Houston, 7500 Cambridge Street, Houston, TX 77054, USA

E-mail:kalu.ogbureke@uth.tmc.edu

Key words: dentin sialophosphoprotein, matrix metalloproteinase 20, oral squamous cell carcinoma, interferon $\gamma$, endoplasmic reticulum stress, unfolded protein response blotting. Cell viability, apoptosis and migration were evaluated by MTT, Annexin V-fluorescein isothiocyanate flow cytometry and wound-healing assays, respectively. IFN $\gamma$ treatment significantly downregulated the mRNA expression levels of the major ER stress regulator GRP78 and, to a lesser extent, the UPR-associated molecule IRE1; however, IFN $\gamma$ had no significant effect on PERK. With regards to ER Ca homeostasis molecules, treatment with IFN $\gamma$ downregulated the mRNA expression levels of SERCA2b and upregulated those of IP3r. Furthermore, DSPP and MMP20 mRNA expression levels were significantly reduced following IFN $\gamma$ treatment. Notably, treatment with IFN $\gamma$ hampered OSC2 migration, reduced cell viability and PCNA protein expression, enhanced apoptosis, downregulated Bcl-2, and upregulated Bax and cytochrome $c$. Overall, IFN $\gamma$ inhibited OSCC cell viability and migration, and increased apoptosis, possibly by regulating ER stress and UPR mechanisms. In addition, IFN $\gamma$-induced DSPP and MMP20 downregulation may correspond with alteration in ER Ca homeostasis.

\section{Introduction}

Oral squamous cell carcinoma (OSCC) is the sixth most common type of cancer worldwide (1). In the United States alone, $>50,000$ new cases are diagnosed annually, resulting in $\sim 10,000$ cases of mortality $(2,3)$. Surgery remains the main treatment option for patients with OSCC, since the currently available chemotherapeutic agents have proved to be of limited success. Therefore, the 5-year survival rate for patients with OSCC over the past four decades remains at 50-55\%, despite novel treatment modalities $(4,5)$. A better understanding of the biological nature of OSCC is required, in order to improve the effectiveness of chemotherapeutic intervention and, consequently, the survival of patients with OSCC.

IFN $\gamma$ is an immune response-stimulating cytokine, which orchestrates several distinct cellular functions. Its role focuses on enhanced immune cell surveillance $(6,7)$ and induction of the major histocompatibility complex response in numerous types of normal and neoplastic cells $(8,9)$. IFN $\gamma$, which is secreted by activated $\mathrm{T}$ cells and natural killer cells, enhances macrophage 
activation, Thelper cell (Th)1/Th2 balance, and regulates cellular proliferation and apoptosis (10). Furthermore, IFN $\gamma$ has been reported to directly attack tumor cells by initiating a cascade of signaling mechanisms that modulate cell viability $(11,12)$. Although the molecular basis of this action remains unclear, previous studies have proposed potential effects of IFN $\gamma$ on endoplasmic reticulum (ER) stress proteins (13-15) and ER calcium (Ca) homeostasis channel pumps (16).

The ER is responsible for protein folding and targeting during protein synthesis, and represents the principal intracellular $\mathrm{Ca}$ storage, which is essential for Ca signaling pathways and the regulation of cellular Ca homeostasis $(17,18)$. Sarco/endoplasmic reticulum Ca-ATPase (SERCA)-type pumps are the major carriers of Ca into the ER lumen, whereas inositol 1,4,5-trisphosphate receptors (IP3r) are family proteins that drive Ca release channels (19). These Ca influx or efflux channels are regulated by Ca-dependent chaperones, including 78-kDa glucose-regulated protein (GRP78), which bind or buffer intraluminal $\mathrm{Ca}(17,20)$.

ER homeostasis is a multifactorial process that is affected by numerous environmental factors, including the redox state, ischemia, nutrient and $\mathrm{Ca}$ level alterations, high protein synthesis rate, and inflammation (21). Persistent stimuli may disrupt proper ER function, thus leading to ER stress. This, in turn, may result in activation of a cascade of signaling molecules and pathways that constitute the unfolded protein response (UPR) $(21,22)$. The main aim of the UPR is to arrest intraluminal accumulation and/or secretion of unfolded proteins and enhance degradation of misfolded proteins $(23,24)$. Protein kinase R-like ER kinase (PERK), activating transcription factor (ATF) $6(\alpha$ and $\beta)$, and the kinase endoribonuclease inositol-requiring enzyme 1 (IRE1), constitute three ER transmembrane protein-sensors that detect alterations in ER homeostasis. Conversely, GRP78 is considered to be the master UPR chaperone that negatively regulates PERK, ATF6 and IRE1 functions (17,25). A nexus between ER stress and cancer has previously been highlighted; UPR alterations may prevent ER stress-induced apoptosis and help cancer cells survive in a otherwise demanding microenvironment (23). Other studies have also revealed that GRP78 cysteine oxidation favors cancer cell survival during stress (22), and SERCA activity has been reported as a potential target for cancer treatment (17).

Dentin sialophosphoprotein (DSPP) is a member of the small integrin-binding ligand $\mathrm{N}$-linked glycoproteins (SIBLINGs) family (26). Within the past decade, the expression of some members of the SIBLINGs family, along with their cognate matrix metalloproteinases (MMPs), have been detected in various types of cancer, including OSCC (27-31). Specifically, our previous studies have indicated that DSPP expression is correlated with the transition of dysplastic oral premalignant lesions to OSCC, with tumor aggressiveness, and with the recurrence of OSCC at histologically negative ('tumor-free') surgical margins of primary OSCC (28-31). DSPP is expressed in the cytoplasm and perinuclear perimeter of OSCC cells, with significantly elevated immunoreactivity in the cytoplasm of poorly differentiated OSCC cells (28).

Our recent study reported a novel finding, that matrix MMP20 is expressed and directly interacts with DSPP in human OSCC tissues and cell lines (32). This finding established MMP20 as the cognate MMP partner of DSPP (32). Furthermore, dentin sialoprotein (DSP), which is the cleaved $\mathrm{N}$-terminal product of DSPP, interacts with MMP20 promoter proximal elements (32). An earlier report by Joshi et al demonstrated that DSPP silencing in OSCC cells results in MMP2, MMP3, MMP9, vascular endothelial growth factor, p53, Ki-67 and epidermal growth factor receptor downregulation, as well as altered cell morphology, cell proliferation, colony-formation and invasion of OSCC cells (33). In addition, DSPP silencing increases cisplatin sensitivity and enhances apoptosis of OSCC cells, whereas subcutaneous injection of OSCC xenografted $\mathrm{Balb} / \mathrm{c}$ nude mice with DSPP-silenced OSCC cells results in attenuated tumor growth (33). Our recent report proposed a tumorigenic role for DSPP in OSCC cells, and presented a relationship between DSPP and the ER chaperone GRP78 (34). Furthermore, our report suggested a DSPP-associated modulatory effect on ER stress, Ca homeostasis and UPR proteins, including sarco/endoplasmic reticulum $\mathrm{Ca}^{2+}$-ATPase (SERCA2b), IRE1, PERK and ATF6 (34).

The present study aimed to investigate the role of IFN $\gamma$ signaling in DSPP expression. The study aimed to elucidate a potential connection between this interaction and ER homeostasis, and suggested an alternative mechanism responsible for IFN $\gamma$-induced effects on OSCC cells. Therefore, the effects of IFN $\gamma$ treatment on specific ER stress-associated proteins, including SERCA2b, IP3r, GRP78, IRE1 and PERK, were investigated in the OSC2 OSCC cell line, and its effects on tumor cell proliferation, migration and apoptosis were analyzed.

\section{Materials and methods}

Human cell lines and culture conditions. The previously characterized human OSCC cell line, OSC2, which was originally obtained from the American Type Culture Collection (Manassas, VA, USA) and routinely authenticated in our laboratory, was used for this study. Cells were cultured as a monolayer in Dulbecco's modified Eagle's medium (DMEM)/F12 supplemented with $10 \%$ fetal bovine serum (FBS; Gibco; Thermo Fisher Scientific, Inc., Waltham, MA, USA), $1 \%$ penicillin/streptomycin and $500 \mathrm{ng} / \mathrm{ml}$ hydrocortisone (Sigma Aldrich; Merck $\mathrm{KGaA}$, Darmstadt, Germany), and were maintained at $37^{\circ} \mathrm{C}$ in a humidified atmosphere containing $5 \% \mathrm{CO}_{2}$. Recombinant human IFN $\gamma$ was purchased from Abcam (Cambridge, MA, USA). For all experiments, OSC2 cells were plated and cultured for $48 \mathrm{~h}$ prior to the addition of IFN $\gamma$ at a concentration of $500 \mathrm{U} / \mathrm{ml}$ for 24 or $48 \mathrm{~h}$ at $37^{\circ} \mathrm{C}$. Time-points were chosen with regards to time-response experiments on interferon-regulated factor 1 (IRF1) mRNA expression following treatment with $500 \mathrm{U} / \mathrm{ml} \mathrm{IFN} \gamma$ for $6,12,24$ or $48 \mathrm{~h}$.

Reverse transcription-quantitative polymerase chain reaction (RT-qPCR) analysis. Total RNA was extracted from cells using TRIzol ${ }^{\circledR}$ reagent (cat. no. 15596-026; Invitrogen; Thermo Fisher Scientific, Inc.), according to a standardized protocol, and the concentration of each sample was determined. The qSTAR qPCR primer pairs against human genes had the following sequences (5'-3'): IRF1, forward CGAATCGCTC CTGCAGCAGA, reverse GCCCAGCTCCGGAACAAACA; DSPP, forward CAACCATAGAGAAAGCAAACGCG, reverse TTTCTGTTGCCACTGCTGGGAC; MMP20, forward GAC CAGACCACAATGAACGT, reverse GTCCACTTCTCAGG ATTGTC; PERK, forward ATCCCCCAT GGAACGACCTG, reverse ACCCGCCAGGGACAAAAATG; SERCA2b, forward 
TCATCTTCCAGATCACACCGC, reverse GTCAAGACCA GAACATATC; IP3r, forward GGTTTCATTTGCAAGTTAA TAAAG, reverse AATGCTTTCATGGAACACTCGGTC; IRE1, forward CGGGAATTCG GCCGAGTCCTCGCCATG, reverse CAAGCGGCCGCCTTTCCCAACTATCACCAC GCT; GRP78, forward TGTTCAACCAATTATCAGCAA ACTC, reverse TTCTGCTGTATCCTCTTCACCAGT; and $\beta$-actin, forward GTCTCCTCTGACTTCAACAGCG and reverse ACCACCCTGTTGCTGTAGCCAA.

Total RNA $(1 \mu \mathrm{g})$ was reverse transcribed using iScript RT Supermix (cat. no. 1708841; Bio-Rad Laboratories, Inc., Hercules, CA, USA), according to the manufacturer's protocol. qPCR was performed using synthesized cDNA on a qPCR machine using iTaq ${ }^{\mathrm{TM}}$ UniverSYBR $^{\circledR}$ Green PCR Master Mix (cat. no. 1725124; Bio-Rad Laboratories, Inc.). PCR thermocycling was conducted as follows: $94^{\circ} \mathrm{C}$ for $5 \mathrm{~min}$, followed by 40 cycles at $94^{\circ} \mathrm{C}$ for $30 \mathrm{sec}, 60^{\circ} \mathrm{C}$ for $20 \mathrm{sec}$ and $72^{\circ} \mathrm{C}$ for $40 \mathrm{sec}$, and a final extension step at $72^{\circ} \mathrm{C}$ for $5 \mathrm{~min}$. A standard curve was generated from three serial dilutions of cDNA. Samples, including negative controls, were analyzed in triplicate, and PCR products were verified using dissociation curve analysis. mRNA expression levels were normalized to actin and were analyzed using Bio-Rad CFX manager software (Version 3.0; Bio-Rad Laboratories, Inc.).

Western blot analysis. Western blot analysis was performed as previously described (34). Briefly, cells were lysed and sonicated $(20 \mathrm{kHz}, 2 \times 10 \mathrm{sec})$ in radioimmunoprecipitation assay lysis buffer (Thermo Fisher Scientific, Inc.). Subsequently, equal amounts of protein (30-50 $\mu \mathrm{g}$, depending on the particular protein), as determined by the Bradford protein assay method, were separated by $10 \%$ SDS-PAGE, and electrophoretically separated proteins were transferred to polyvinylidene difluoride membranes (Bio-Rad Laboratories, Inc.). Blotted membranes were then placed in blocking solution (PBS- $0.5 \%$ Tween-20, Sigma-Aldrich; Merck KGaA) for $1 \mathrm{~h}$ at room temperature prior to probing with the following primary antibodies, which were purchased from Santa Cruz Biotechnology, Inc. (Dallas, TX, USA): Mouse monoclonal B-cell lymphoma 2 (Bcl-2; cat. no. sc-7382, 1:250); mouse monoclonal Bcl-2-associated X protein (Bax; cat. no. sc-7480, 1:200); rabbit polyclonal cytochrome $c$ (cat. no. sc-7159, 1:200) and rabbit polyclonal proliferating cell nuclear antigen (PCNA; cat. no. sc-7907, 1:200) overnight at $4^{\circ} \mathrm{C}$. The membranes were washed thoroughly with PBS (Sigma Aldrich; Merck KGaA), and then incubated with goat polyclonal anti-rabbit immunoglobulin $\mathrm{G}$ (IgG) horseradish peroxidase-conjugated secondary antibody (cat. no. sc-2301, 1:3,000; Santa Cruz Biotechnology, Inc.) or anti-mouse $\operatorname{IgG}$ horseradish peroxidase-conjugated secondary antibody (cat. no. sc-2031, 1:3,000; Santa Cruz Biotechnology, Inc.) with agitation at room temperature for $1 \mathrm{~h}$. $\beta$-actin $(1: 2,000)$ was used as a loading control (cat. no. sc-47778; Santa Cruz Biotechnology, Inc.). Proteins were visualized using an enhanced chemiluminescence (ECL) system (Pierce ${ }^{\mathrm{TM}}$ ECL; Thermo Fisher Scientific, Inc.) and band intensity was semi-quantified using ImageJ software 1.48 (National Institutes of Health, Bethesda, MD, USA).

MTT assay. Cell viability was assessed by detecting the conversion of MTT to formazan via mitochondrial oxidation.

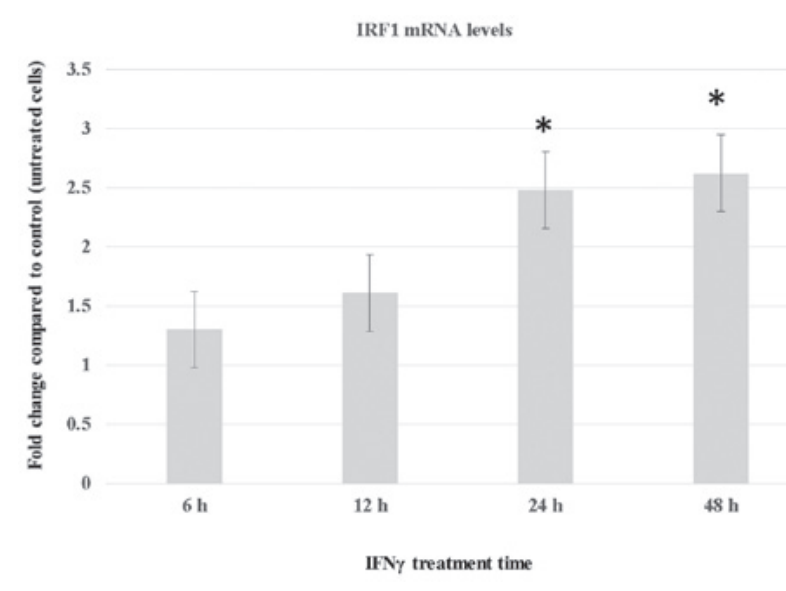

Figure 1. Reverse transcription-quantitative polymerase chain reaction analysis of IRF1 mRNA expression following treatment of OSC2 cells with $500 \mathrm{U} / \mathrm{ml}$ IFN $\gamma$ for various time periods. IRF1 expression was increased in the 24 and $48 \mathrm{~h}$ groups. Results are expressed as fold changes relative to the expression levels in the control (untreated) group. Data are presented as the means \pm standard error of the mean, and each experiment was performed in triplicate. ${ }^{*} \mathrm{P}<0.05$ vs. the control group. IFN $\gamma$, interferon $\gamma$; IRF1, interferon-regulated factor 1.

IFN $\gamma$-treated and untreated OSC 2 cells, at a density of $5 \times 10^{3}$ cells/well, were incubated with $0.5 \mathrm{mg} / \mathrm{ml}$ MTT for $3 \mathrm{~h}$ at room temperature in 96-well plates after 24 and $48 \mathrm{~h}$ in culture. The formation of insoluble formazan purple crystals indicated the presence of viable cells. Crystals were dissolved in dimethyl sulfoxide and the optical density (OD) of the solutions was measured using a spectrophotometer at a wavelength of $570 \mathrm{~nm}$. Assays were performed in triplicate and data are expressed as the means of OD values \pm standard deviation.

Apoptosis analysis by flow cytometry. For apoptosis analyses, Annexin V/propidium iodide (PI; Sigma Aldrich; Merck $\mathrm{KGaA}$ ) staining of IFN $\gamma$-treated and untreated OSC 2 cells was conducted after 24 and $48 \mathrm{~h}$. Briefly, cells were washed with $1 \mathrm{X}$ PBS and resuspended at $10^{6} \mathrm{cells} / \mathrm{ml}$ in Annexin V-binding buffer, before aliquoting the suspension into $100 \mu \mathrm{l} /$ tube fractions. Subsequently, $5 \mu \mathrm{l}$ Annexin V-fluorescein isothiocyanate (FITC) and $10 \mu \mathrm{l}$ PI buffer were added to each tube and cells were incubated in the dark for $15 \mathrm{~min}$ at room temperature. Finally, $400 \mu 1 \mathrm{1X}$ Annexin V-binding buffer was added to each tube and flow cytometric analysis was conducted within $1 \mathrm{~h}$. Samples were analyzed on a FACSCalibur flow cytometer (BD Biosciences, San Jose, CA, USA). Gates in the right angle scatter versus forward scatter diagrams were used to exclude debris. At least 100,000 events were collected prior to analysis. All flow cytometric data were analyzed using BD CellQuest Pro software (Version 5.0; BD Biosciences).

Scratch wound-healing assay. OSC2 cells were cultured until they reached $90 \%$ confluence in $35-\mathrm{mm}$ dishes. Subsequently, scratches were generated using a sterile $200-\mu 1$ pipette tip prior to cells being treated with IFN $\gamma$ for 24 or $48 \mathrm{~h}$. The border of the denuded area was immediately marked with a fine line, and cells were incubated in DMEM/F12 supplemented with $10 \%$ FBS. Images of the cell cultures were captured at 24 and $48 \mathrm{~h}$ using an inverted phase contrast microscope (Olympus Corporation, Tokyo, Japan). Assays were performed in duplicate. 


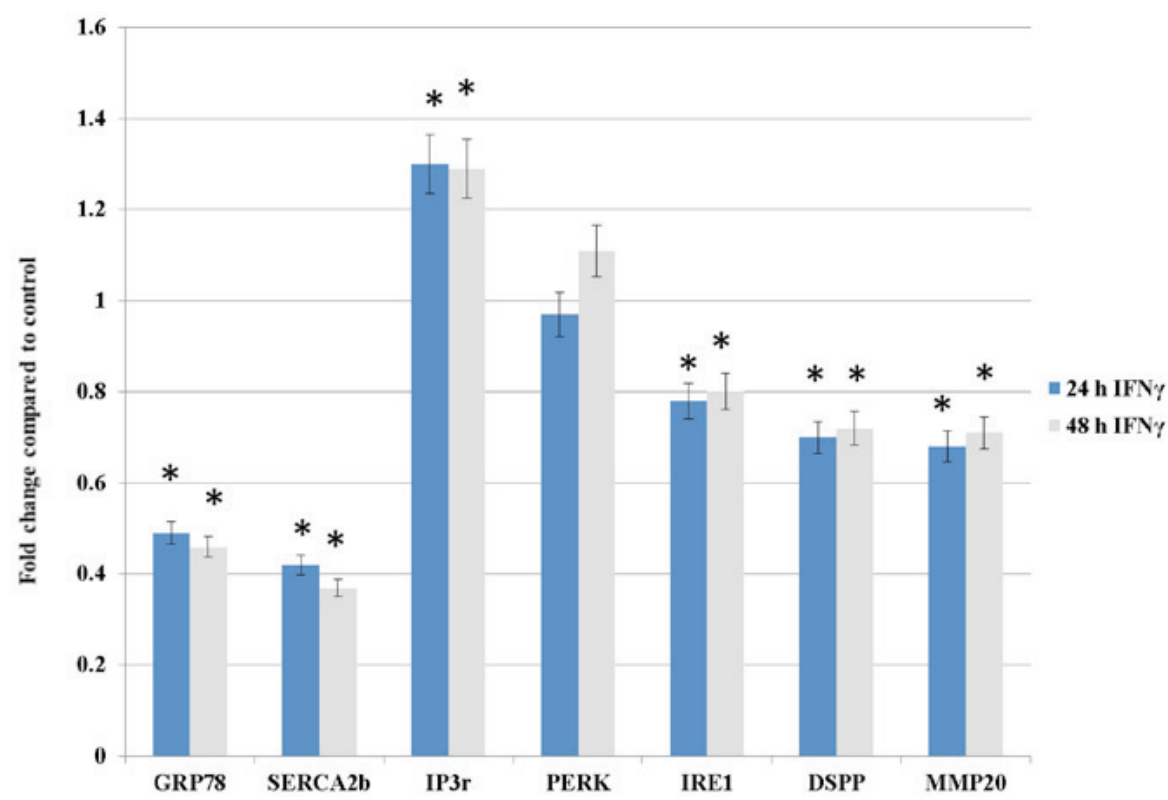

Figure 2. Effects of IFN $\gamma$ treatment (500 U/ml for 24 or $48 \mathrm{~h}$ ) on the mRNA expression levels of proteins associated with ER stress, the unfolded protein response and Ca homeostasis, as well as DSPP and MMP20, as assessed by reverse transcription-quantitative-polymerase chain reaction analysis. DSPP, MMP20, GRP78, SERCA2b and, to a lesser extent, IRE1 exhibited statistically significant decreases at both time-points compared with the control group. Conversely, IP3r mRNA expression was significantly increased at both time-points compared with the control group, whereas PERK mRNA expression was not significantly increased in response to IFN $\gamma$. Results are expressed as fold changes relative to the expression levels in the control (untreated) group. Data are presented as the means \pm standard error of the mean, and each experiment was performed in triplicate. " $\mathrm{P}<0.05$ vs. the control group. DSPP, dentin sialophosphoprotein; ER, endoplasmic reticulum; GRP78, 78-kDa glucose-regulated protein; IFN $\gamma$, interferon $\gamma$; IP3r, inositol 1,4,5-trisphosphate receptor; IRE1, inositol-requiring enzyme 1; MMP20, matrix metalloproteinase 20; PERK, protein kinase R-like ER kinase; SERCA2b, sarco/endoplasmic reticulum Ca ${ }^{2+}$-ATPase.

Statistical analysis. Results from IFN $\gamma$-treated cells were compared with results from untreated (control) cells. Statistical analyses were performed using SPSS version 21 (IBM Corp., Armonk, NY, USA). Paired groups were compared using Student's t-test, whereas one-way analysis of variance was applied for the comparison of multiple groups, followed by post hoc pairwise comparisons with the application of Dunn's test. All experiments were performed in triplicate. $\mathrm{P}<0.05$ was considered to indicate a statistically significant difference.

\section{Results}

IFN $\gamma(500 \mathrm{U} / \mathrm{ml})$ activates intracellular molecular signaling networks at specific time-points. The synthesis of IRF1 is induced by IFN $\gamma$ (35). Therefore, to determine whether the selected dose of $500 \mathrm{U} / \mathrm{ml}$ IFN $\gamma$ effectively activated intracellular molecular signaling pathways, alterations in the mRNA expression levels of IRF1 were monitored by RT-qPCR analyses in a time-dependent assay. As shown in Fig. 1, the mRNA expression levels of IRF1 exhibited a statistically significant time-dependent increase in cells treated for 24 and $48 \mathrm{~h}$ compared with the control cells $(0 \mathrm{~h})$. Since 24 and $48 \mathrm{~h}$ IFN $\gamma$ treatment resulted in an increased IFN $\gamma$ response, these time-points (24 and $48 \mathrm{~h})$ and dose $(500 \mathrm{U} / \mathrm{ml})$ were selected for subsequent experiments.

IFN $\gamma$ treatment downregulates DSPP, MMP20, GRP78, SERCA2b and IRE1, but upregulates IP3r and PERK in OSC2 cells. To evaluate the effects of IFN $\gamma$ treatment on DSPP and MMP20, as well as on the ER stress response, UPR and $\mathrm{Ca}$ homeostasis, alterations in the mRNA expression levels of DSPP, MMP20, GRP78, SERCA2b, IP3r, PERK and
Table I. Summary of upregulated/downregulated mRNAs following treatment of OSC2 cells with interferon $\gamma$.

\begin{tabular}{lcc}
\hline Gene type & Upregulated & Downregulated \\
\hline SIBLING & - & DSPP \\
DSPP cognate partner & - & MMP20 \\
Ca homeostasis & IP3r & SERCA2b \\
ER chaperone & - & GRP78 \\
UPR-associated proteins & - & IRE1 \\
Apoptosis-associated & Bax; cytochrome $c$ & Bcl-2 \\
proteins & & \\
Proliferation-associated & - & PCNA \\
proteins & & \\
\hline
\end{tabular}

Bax, Bcl-2-associated X protein; Bcl-2, B-cell lymphoma 2; DSPP, dentin sialophosphoprotein; ER, endoplasmic reticulum; GRP78, 78-kDa glucose-regulated protein; IP3r, inositol 1,4,5-trisphosphate receptor; IRE1, inositol-requiring enzyme 1; MMP20, matrix metalloproteinase 20; PERK, protein kinase R-like ER kinase; PCNA, proliferating cell nuclear antigen; SERCA2b, sarco/endoplasmic reticulum $\mathrm{Ca}^{2+}$-ATPase; SIBLING, small integrin-binding ligand $\mathrm{N}$-linked glycoprotein; UPR, unfolded protein response.

IRE1 were determined by RT-qPCR analysis at 24 and $48 \mathrm{~h}$ intervals. Table I summarizes the upregulated/downregulated genes detected following treatment of OSC2 cells with IFN $\gamma$. As shown in Fig. 2, DSPP, MMP20, GRP78, SERCA2b and, to a lesser extent, IRE1, exhibited statistically significant differences $(\mathrm{P}<0.05)$. These results suggested that IFN $\gamma$ treatment 
A

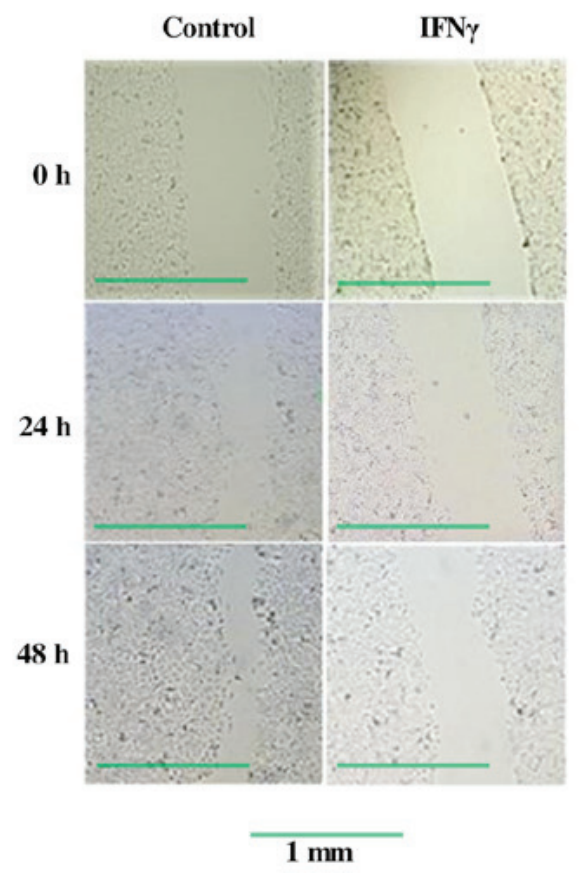

B

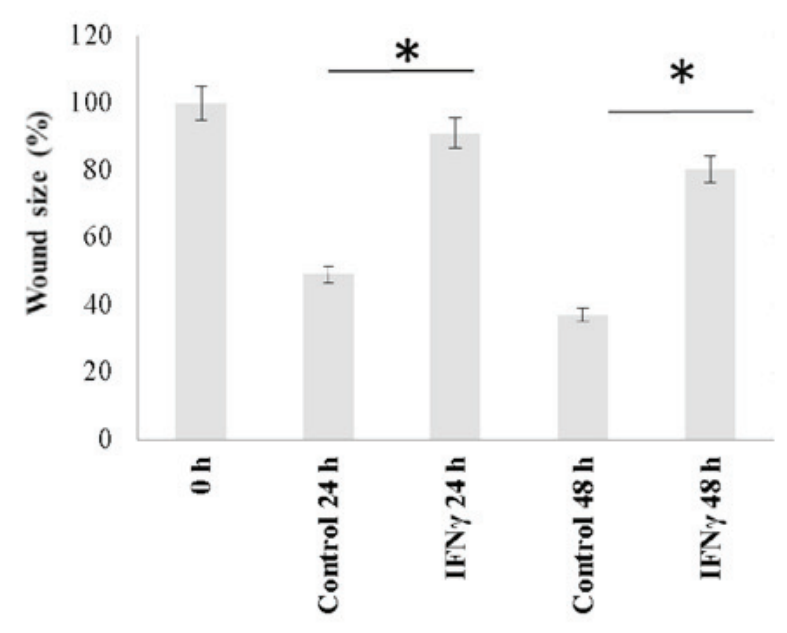

Figure 3. Effects of IFN $\gamma$ treatment $(500 \mathrm{U} / \mathrm{ml}$ for 24 or $48 \mathrm{~h}$ ) on OSC2 cells after scratch wound generation on the migratory capacity of OSC2 cells. (A) Representative images of confluent monolayers of OSC 2 cells, which were scratched using a $200-\mu 1$ pipette tip. Images were captured at the indicated time-points after wound generation. (B) Mean values of wound size (\%) in two independent experiments. IFN $\gamma$ treatment significantly delayed wound closure compared with in the untreated control groups at both time-points. Data are presented as the means \pm standard error of the mean, and each experiment was performed in triplicate. " $\mathrm{P}<0.05$. IFN $\gamma$, interferon $\gamma$.

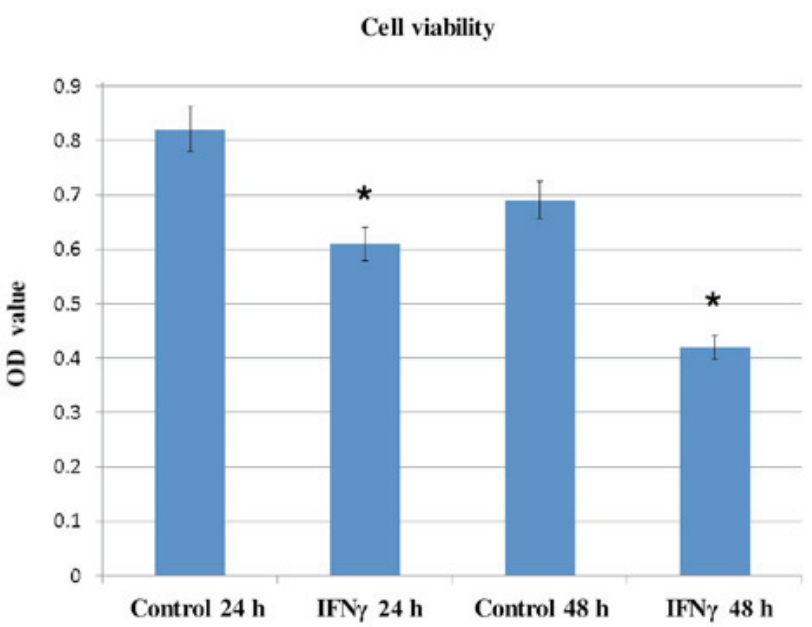

Figure 4. Effects of IFN $\gamma$ treatment $(500 \mathrm{U} / \mathrm{ml}$ for 24 or $48 \mathrm{~h}$ ) on OSC2 cell proliferation, as determined by the MTT colorimetric assay. IFN $\gamma$-treated OSC2 cells exhibited significantly lower OD values compared with the control cells at both time-points. Data are presented as the means \pm standard error of the mean, and each experiment was performed in triplicate. ${ }^{*} \mathrm{P}<0.05$ vs. the control groups. IFN $\gamma$, interferon $\gamma$; OD, optical density.

may affect ER Ca homeostasis by suppressing SERCA2b and inducing IP3r. Furthermore, the results suggested that the IFN $\gamma$-induced downregulation of GRP78, and the modest effects on UPR-associated proteins IRE1 and PERK, may induce ER stress.

IFN $\gamma$ treatment decreases $\mathrm{OSC} 2$ cell migration. To assess the effects of IFN $\gamma$ treatment on the migratory capacity of OSC2 cells, the rate of scratch wound closure on cell culture plates was determined. As shown in Fig. 3, IFN $\gamma$ treatment of cells significantly delayed wound closure compared with the control cells at 24 and $48 \mathrm{~h}(\mathrm{P}<0.05)$. This finding may be associated with the significantly reduced MMP20 mRNA expression detected in IFN $\gamma$-treated cells compared with in the control cells $(\mathrm{P}<0.05$; Fig. 2$)$, and suggested that IFN $\gamma$ may regulate the migratory capacity of OSC 2 cells, possibly by suppressing MMP20 along with its cognate partner DSPP.

IF $\gamma \gamma$ treatment inhibits proliferation and increases apoptosis of OSC 2 cells. To analyze mitochondrial activity following treatment of OSC 2 cells with IFN $\gamma$ for various time-points, the MTT colorimetric assay was conducted. As shown in Fig. 4, IFN $\gamma$-treated cells exhibited significantly lower OD values at 24 and $48 \mathrm{~h}$ compared with the control cells $(\mathrm{P}<0.05)$, thus indicating that $\mathrm{OSC} 2$ cell proliferation was reduced following IFN $\gamma$ treatment. This observation is consistent with the results of western blotting; IFN $\gamma$ treatment induced a reduction in the expression levels of the cell proliferation-associated marker PCNA (Fig. 5). In order to assess the rate of apoptosis, IFN $\gamma$-treated OSC 2 cells were analyzed by Annexin V-FITC flow cytometry and apoptotic rates were compared with the control (untreated) group. Cell sorting indicated that the apoptotic cell fraction was significantly increased from $3.51 \%$ in the untreated control group to 16.8 and $27.6 \%$ in IFN $\gamma$-treated cells at 24 and $48 \mathrm{~h}$, respectively (Fig. 6). This finding is consistent with the upregulation in the protein expression levels of pro-apoptotic molecules, Bax and cytochrome $c$, and the downregulation of the anti-apoptotic molecule, Bcl-2, as shown in Fig. 5. Taken together, these results suggested that 


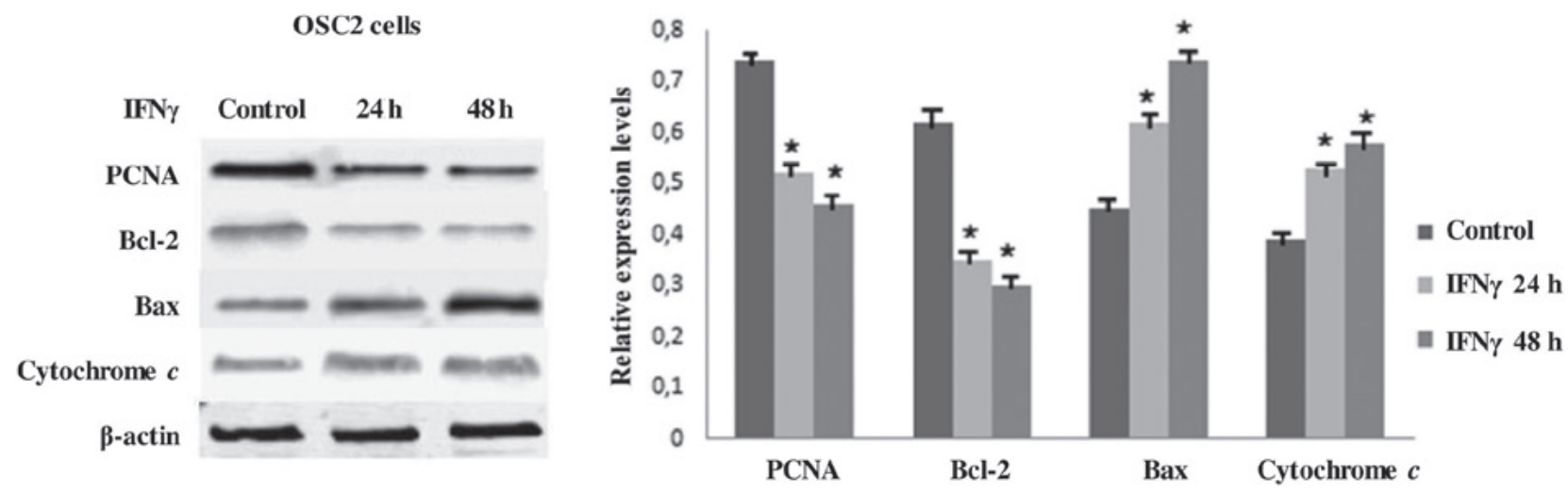

Figure 5. IFN $\gamma$ treatment $(500 \mathrm{U} / \mathrm{ml}$ for 24 or $48 \mathrm{~h}$ ) affects the expression of cell proliferation- and apoptosis-associated proteins in OSC2 cells. Western blotting revealed that PCNA and Bcl-2 protein expression levels were decreased, whereas Bax and cytochrome $c$ levels were increased in IFN $\gamma$-treated OSC2 cells compared with the control cells. Data are presented as the means \pm standard error of the mean, and each experiment was performed in triplicate. ${ }^{*} \mathrm{P}<0.05$ vs. the control groups. Bax, Bcl-2-associated X protein; Bcl-2, B-cell lymphoma 2; IFN $\gamma$, interferon $\gamma$; PCNA, proliferating cell nuclear antigen.

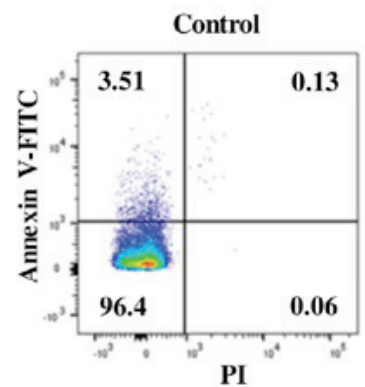

IFN $\gamma 24$ h

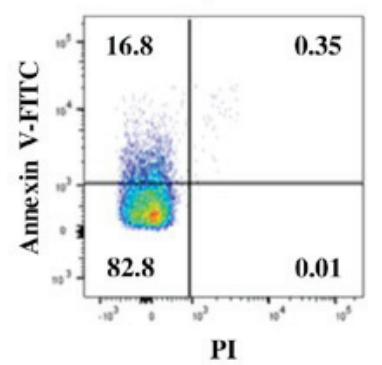

IFNy 48 h

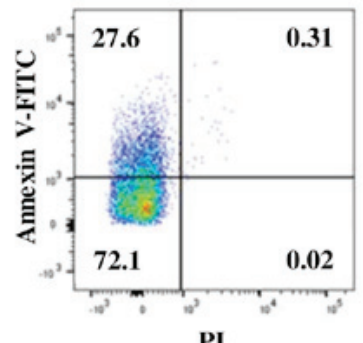

PI

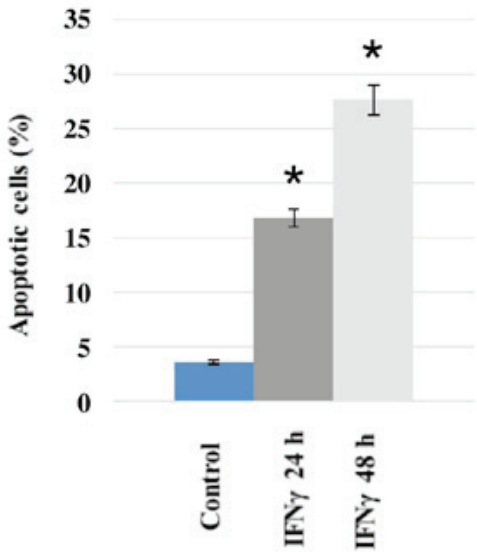

Figure 6. Rate of apoptosis in IFN $\gamma$-treated ( $500 \mathrm{U} / \mathrm{ml}$ for 24 or $48 \mathrm{~h}$ ) OSC2 cells, as analyzed by Annexin V-FITC flow cytometry; apoptosis was compared with rates in control (untreated) cells. Apoptotic cells were significantly increased from $3.51 \%$ in the control group to $16.8(24 \mathrm{~h})$ and $27.6 \%$ (48 h) in IFN $\gamma$-treated cells. Data are presented as the means \pm standard error of the mean, and each experiment was performed in triplicate. "P $<0.05$ vs. the control group. FITC, fluorescein isothiocyanate; IFN $\gamma$, interferon $\gamma$; PI, propidium iodide.

IFN $\gamma$ may exert an antitumor effect on OSC2 cells by reducing cell proliferation and enhancing apoptosis.

\section{Discussion}

To the best of our knowledge, the present study is the first to determine the various effects of IFN $\gamma$ treatment on the mRNA expression levels of DSPP and MMP20,ER Ca homeostasis,ER stress- and UPR-associated proteins, and on notable hallmarks of oral carcinogenesis in OSCC cells. The downregulation of DSPP and MMP20 mRNA expression following IFN $\gamma$ treatment may account for the reduced migratory potential of OSC2 cells. Our previous report revealed that the strong binding of DSP to MMP20, and its interaction with the promoter proximal element of MMP20, may account for increased migration, invasion and metastasis in OSCC (32). Recently, we reported that DSPP silencing results in significantly reduced MMP20 mRNA expression and in reduced migration of OSCC cells (34). Other investigators have reported that IFN $\gamma$ and IFN $\beta$ suppress MMP9 expression through a signal transducer and activator of transcription (STAT) $1 \alpha$ pathway in primary astrocytes and human fibrosarcoma cells (36), and that IFN $\gamma$ treatment reduces migration of A172 human glioblastoma cells (37). IFN $\gamma$ also inhibits MMP3-induced invasiveness of T98G glioma cells (38). Therefore, the effects of DSPP and MMP20 downregulation on the notable hallmarks of oral carcinogenesis, including decreased cell viability and migration, and increased apoptosis, noted in the present study 
following treatment of OSC 2 cells with IFN $\gamma$ are consistent with our previous findings $(33,34)$.

It has previously been suggested that IFNs enhance apoptosis in acute promyelocytic leukemia, chronic myelogenous leukemia, multiple myeloma, melanoma and ovarian cancer (39). Specifically, several reports have highlighted the effects of IFN $\gamma$ on head and neck squamous cell carcinoma (HNSCC) cells. For example, a recent report revealed that IFN $\gamma$ induces apoptosis in two HNSCC cell lines, and leads to overexpression and activation of indoleamine 2,3 protein (13). Furthermore, IFN $\gamma$ activates Janus kinase/STAT1, apoptosis signal-regulating kinase $1, \mathrm{p} 38$, c-jun-N-terminal kinase, the nuclear factor- $\kappa \mathrm{B}$ pathway and IRF1 (13). IFN $\gamma$ treatment of OSCC cells has also been revealed to result in downregulation of heat shock protein 27 , which is a proposed anti-apoptotic molecule, and enhancement of cell death (40). Gadkaree et al reported that the antitumor effects of synthetic cyclic dinucleotides are associated with the upregulation of IFN- $\gamma^{+}$cluster of differentiation $8^{+}$infiltrating $\mathrm{T}$ cells and programmed death-L1 protein in a HNSCC xenograft-mouse model (41). Xu et al revealed that IFN $\gamma$ sensitizes HNSCC cells to chemotherapy-induced apoptosis and necroptosis by upregulating early growth response protein 1 (42). Conversely, administration of IFN $\alpha$ or tumor necrosis factor $\alpha$ does not induce considerable alterations in OSCC apoptosis (40).

The present results suggested that IFN $\gamma$ treatment of OSC2 cells suppressed PCNA and Bcl-2 expression, and upregulated Bax and cytochrome $c$ expression; these findings are consistent with previous report of similar effects in human breast, prostate and lung cancer cells. Ning et al reported that IFN $\gamma$, but not IFN $\alpha$ or IFN $\beta$, enhances IRF1 expression in anti-estrogen-resistant human breast cancer cells, and IRF1 induction downregulates the expression of pro-survival proteins, Bcl-2 and Bcl-2-like protein 2, and enhances pro-apoptotic Bcl-2 antagonist/killer (Bak) and Bax activity (43). Furthermore, IFN $\gamma$ enhances the apoptotic effects of polyinosinic:polycytidylic acid in human prostate cancer cells by enhancing Bak expression (44). With regards to human lung cancer cells, IFN $\gamma$ induces phosphorylated-STAT1 activity in cells expressing STAT1-CC, which are hyper-responsive to IFN, thus resulting in downregulation of PCNA and c-fos (45). In OSCC cells of the tongue, Liu et al reported that overexpression of interleukin-18 activates caspase-3, -7 and -9 pathways, and enhances IFN $\gamma$ and cytochrome $c$ mRNA expression (46).

With regards to ER Ca homeostasis-, ER stress- and UPR-associated proteins, the present data revealed that IFN $\gamma$ treatment decreased GRP78 and SERCA2b mRNA expression, and induced IP3r expression. These findings supported the hypothesis that a combination of increased ER Ca leakage (through IP3 channels) and a blockage in $\mathrm{Ca}$ influx (via suppression of SERCA activity) may perturb ER Ca homeostasis and enhance ER stress. Furthermore, the high apoptotic rates observed in response to IFN $\gamma$ treatment of OSC2 cells may be associated with GRP78 downregulation. This speculation is based on the results of previous studies, which provide evidence indicating that GRP78 promotes tumor progression $(47,48)$, and increased GRP78 expression is correlated with shorter recurrence time and poor survival of patients with prostate and breast cancers (49-51). Notably, in response to GRP78 inhibition, the response of patients with prostate cancer to photodynamic therapy is improved (52). In in vitro and animal experiments, GRP78 silencing suppresses tumor cell invasion, cell growth and metastasis in xenograft models of gastric cancer (53).

The present data also indicated that IFN $\gamma$ treatment resulted in moderate downregulation of IRE1 mRNA expression, and a very modest induction of PERK activity after $48 \mathrm{~h}$. These findings are consistent with earlier reports indicating that treatment of pancreatic rat cells with IFN $\gamma$ decreases the basal levels of spliced X-binding protein 1 (XBP1) mRNA; XBP1 is downstream of IRE1 (14). Similarly, Son et al reported that IRE1 silencing results in accelerated $\mathrm{Ca}$ efflux through IP3 $r$ and increased apoptotic rates in human neuroblastoma cells (54), whereas Kanekura et al indicated that IRE1 inhibition enhances ER stress and apoptosis through oligomerization of Bax and Bak proteins (55). With regards to HNSCC cells, an in vitro study by El Jamal et al suggested that IFN $\gamma$ treatment of HNSCC cells triggers ER stress and induces apoptosis by upregulating PERK and IRE1 pathways (13). Furthermore, Fribley et al demonstrated that treatment with Celastrol (a triterpenoid compound isolated from the Celastraceae plant family) mediates the pro-apoptotic UPR effects and apoptosis in OSCC cells via PERK-eukaryotic translation initiation factor 2 (eIF2)-ATF4-C/EBP homologous protein signaling (56). Similarly, Afatinib, which is an inhibitor that targets ErbB family members, triggers the PERK-eIF2 $\alpha$-ATF4 pathway and suppresses protein kinase B-mammalian target of rapamycin activity leading to apoptosis of HNSCC cells (57).

Notably, some studies appear to conflict with the aforementioned findings, suggesting a tumorigenic role for PERK in modulation of ER stress. For example, Fujimoto et al reported that PERK inhibition induces apoptosis of cancer stem cells (58), whereas Koumenis reported that the expression of PERK, and its target molecule eIF2, are correlated with increased tumor growth and survival under hypoxic conditions (59). Furthermore, it has been reported that PERK inhibition decreases tumor growth in vitro and in vivo (60), and hampers metastasis in breast cancer mice xenografts (61).

Our previous study suggested the effects of DSPP on ER stress, the UPR and Ca homeostasis (34), and the present data indicated that treatment of OSC2 cells with IFN $\gamma$ resulted in downregulation of DSPP and MMP20; therefore, it may be hypothesized that DSPP serves an oncogenic role during the ER stress adaptive response in the OSCC microenvironment. Therefore, IFN $\gamma$ treatment-induced DSPP downregulation may be directly associated with the observed alterations in ER homeostasis, at least partially by mediating alterations in major ER stress-associated proteins, including GRP78, SERCA2b and UPR sensor proteins, thus contributing to UPR collapse. Although the mechanisms by which IFN $\gamma$ interacts with DSPP are yet to be fully understood, these mechanisms may include pathways that are yet to be characterized. Overall, the finding that IFN $\gamma$ modified OSCC properties through UPR modifications warrants further investigation.

It has been suggested that the UPR serves a dual role in cancer biology: Firstly, to ameliorate ER stress-associated damage; and secondly, to activate apoptotic pathways in severe conditions (22). For this reason, it is often difficult to predict whether, or for how long, UPR proteins inhibit tumor growth, or protect cancer cells within the tumor microenvironment (62). 
It would appear that the duration and severity of ER stress determines the survival or apoptotic death of cancer cells (62). Conflicting reports regarding the effects of UPR protein expression on cancer cell fate may reflect the fact that individual UPR protein modifications result in opposing signals between induction and attenuation under ER stress $(62,63)$.

In conclusion, the present data strongly supported an antitumor role for IFN $\gamma$ in OSCC cells through mechanisms that downregulate DSPP and MMP20, leading to disturbances in ER homeostasis, and alterations in proteins associated with ER stress and Ca regulation. Notably, treatment of OSCC cells with IFN $\gamma$ also decreased cell viability and migration, and increased apoptosis. Therefore, it may be speculated that either IFN $\gamma$ interacts with DSPP, which, in turn, at least partially mediates the observed effects on ER stress molecules, or, alternatively, DSPP modifications follow IFN $\gamma$ treatment-induced alterations in ER homeostasis. A recognized limitation of the present study is the focus on the alterations in the mRNA expression levels of genes encoding ER stressor UPR-associated proteins. Nevertheless, the data obtained presents background information for the design of additional studies investigating alterations in protein expression and related functional mechanisms. Therefore, further studies beyond the scope of the present report may help to elucidate the sequential mechanisms underlying IFN $\gamma$-DSPP interaction in OSCC, and the consequential effects on ER stress response. These studies aim to provide insight into potential targeted therapeutic methods and interventional strategies for the treatment of patients with OSCC.

\section{Acknowledgements}

Not applicable.

\section{Funding}

This study was supported by faculty startup research funding (to KUEO) from the University of Texas Health Science Center at Houston (Houston, TX, USA)

\section{Availability of data and materials}

The datasets used and/or analyzed in the present study are available from the corresponding author on reasonable request.

\section{Authors' contributions}

NGN and KUEO made substantial contributions to the conception and design of the study, reviewed data, reviewed/edited draft manuscripts, and reviewed/edited the final draft of the manuscript. IG and JA carried out experiments related to the study, acquired, analyzed and interptreted data, and provided the initial draft of the manuscript. All authors gave their approval of the final draft of the manuscript, and agree to be accountable for all aspects of the study related to accuracy or integrity of all parts of the study.

\section{Ethics approval and consent to participate}

Not applicable.

\section{Patient consent for publication}

Not applicable.

\section{Competing interests}

The authors declare that they have no competing interests.

\section{References}

1. Irani S: Distant metastasis from oral cancer: A review and molecular biologic aspects. J Int Soc Prev Community Dent 6: 265-271, 2016.

2. Simard EP, Torre LA and Jemal A: International trends in head and neck cancer incidence rates: Differences by country, sex and anatomic site. Oral Oncol 50: 387-403, 2014.

3. Russo D, Merolla F, Mascolo M, Ilardi G, Romano S, Varricchio S, Napolitano V, Celetti A, Postiglione L, Di Lorenzo PP, et al: FKBP51 immunohistochemical expression: A new prognostic biomarker for OSCC? Int J Mol Sci 18: 443, 2017.

4. Silverman S Jr: Demographics and occurrence of oral and pharyngeal cancers. The outcomes, the trends, the challenge. J Am Dent Assoc 132 (Suppl): S7-S11, 2001.

5. Kujan O, Glenny AM, Duxbury J, Thakker N and Sloan P: Evaluation of screening strategies for improving oral cancer mortality: A Cochrane systematic review. J Dent Educ 69: 255-265, 2005.

6. Wakita D, Chamoto K, Ohkuri T, Narita Y, Ashino S, Sumida K, Nishikawa H, Shiku H, Togashi Y, Kitamura H, et al: IFN-gamma-dependent type 1 immunity is crucial for immunosurveillance against squamous cell carcinoma in a novel mouse carcinogenesis model. Carcinogenesis 30: 1408-1415, 2009.

7. Hayakawa Y, Sato-Matsushita M, Takeda K, Iwakura Y, Tahara H and Irimura T: Early activation and interferon- $\gamma$ production of tumor-infiltrating mature CD27 high natural killer cells. Cancer Sci 102: 1967-1971, 2011.

8. Hong M, Jiang Z and Zhou YF: Effects of thermotherapy on Th1/Th2 cells in esophageal cancer patients treated with radiotherapy. Asian Pac J Cancer Prev 15: 2359-2362, 2014.

9. Chen J, Hou J, Zhang J, An Y, Zhang X, Yue L, Liu J and Li X: Atorvastatin synergizes with IFN- $\gamma$ in treating human non-small cell lung carcinomas via potent inhibition of RhoA activity. Eur J Pharmacol 682: 161-170, 2012.

10. Gattoni A, Parlato A, Vangieri B, Bresciani M and Derna R: Interferon-gamma: Biologic functions and $\mathrm{HCV}$ therapy (type I/II) (1 of 2 parts). Clin Ter 157: 377-386, 2006.

11. Chung TW, Tan KT, Chan HL, Lai MD, Yen MC, Li YR, Lin SH and Lin CC: Induction of indoleamine 2,3-dioxygenase (IDO) enzymatic activity contributes to interferon-gamma induced apoptosis and death receptor 5 expression in human non-small cell lung cancer cells. Asian Pac J Cancer Prev 15: 7995-8001, 2014.

12. Hastie C: Interferon gamma, a possible therapeutic approach for late-stage prostate cancer? Anticancer Res 28B: 2843-2849, 2008.

13. El Jamal SM, Taylor EB, Abd Elmageed ZY, Alamodi AA, Selimovic D, Alkhateeb A, Hannig M, Hassan SY, Santourlidis S, Friedlander PL, et al: Interferon gamma-induced apoptosis of head and neck squamous cell carcinoma is connected to indoleamine-2,3-dioxygenase via mitochondrial and ER stress-associated pathways. Cell Div 11: 11, 2016.

14. Pirot P, Eizirik DL and Cardozo AK: Interferon-gamma potentiates endoplasmic reticulum stress-induced death by reducing pancreatic beta cell defence mechanisms. Diabetologia 49: 1229-1236, 2006.

15. Watanabe Y, Suzuki O, Haruyama $T$ and Akaike T: Interferon-gamma induces reactive oxygen species and endoplasmic reticulum stress at the hepatic apoptosis. J Cell Biochem 89: 244-253, 2003.

16. Cardozo AK, Ortis F, Storling J, Feng YM, Rasschaert J, Tonnesen M, Van Eylen F, Mandrup-Poulsen T, Herchuelz A and Eizirik DL: Cytokines downregulate the sarcoendoplasmic reticulum pump $\mathrm{Ca}^{2+}$ ATPase $2 \mathrm{~b}$ and deplete endoplasmic reticulum $\mathrm{Ca}^{2+}$, leading to induction of endoplasmic reticulum stress in pancreatic beta-cells. Diabetes 54: 452-461, 2005. 
17. Denmeade SR and Isaacs JT: The SERCA pump as a therapeutic target: Making a 'smart bomb' for prostate cancer. Cancer Biol Ther 4: 14-22, 2005.

18. Rao RV, Hermel E, Castro-Obregon S, del Rio G, Ellerby LM, Ellerby HM and Bredesen DE: Coupling endoplasmic reticulum stress to the cell death program. Mechanism of caspase activation. J Biol Chem 276: 33869-33874, 2001.

19. Foskett JK, White C, Cheung KH and Mak DO: Inositol trisphosphate receptor $\mathrm{Ca}^{2+}$ release channels. Physiol Rev 87: 593-658, 2007.

20. Papp S, Dziak E, Michalak M and Opas M: Is all of the endoplasmic reticulum created equal? The effects of the heterogeneous distribution of endoplasmic reticulum $\mathrm{Ca}^{2+}$-handling proteins. J Cell Biol 160: 475-479, 2003.

21. Giampietri C, Petrungaro S, Conti S, Facchiano A, Filippini A and Ziparo E: Cancer microenvironment and endoplasmic reticulum stress response. Mediators Inflamm 2015: 417281, 2015.

22. Wang M and Kaufman RJ: The impact of the endoplasmic reticulum protein-folding environment on cancer development Nat Rev Cancer 14: 581-597, 2014.

23. Yadav RK, Chae SW, Kim HR and Chae HJ: Endoplasmic reticulum stress and cancer. J Cancer Prev 19: 75-88, 2014.

24. Lemus L and Goder V: Regulation of endoplasmic reticulum-associated protein degradation (ERAD) by Ubiquitin Cells 3: 824-847, 2014.

25. Bertolotti A, Zhang Y, Hendershot LM, Harding HP and Ron D: Dynamic interaction of BiP and ER stress transducers in the unfolded-protein response. Nat Cell Biol 2: 326-332, 2000.

26. Fisher LW and Fedarko NS: Six genes expressed in bones and teeth encode the current members of the SIBLING family of proteins. Connect Tissue Res 44 (Suppl 1): 33-40, 2003.

27. Bellahcène A, Castronovo V, Ogbureke KU, Fisher LW and Fedarko NS: Small integrin-binding ligand N-linked glycoproteins (SIBLINGs): Multifunctional proteins in cancer. Nat Rev Cancer 8: 212-226, 2008.

28. Ogbureke KU, Nikitakis NG, Warburton G, Ord RA, Sauk JJ, Waller JL and Fisher LW: Up-regulation of SIBLING proteins and correlation with cognate MMP expression in oral cancer. Oral Oncol 43: 920-932, 2007.

29. Ogbureke KU, Abdelsayed RA, Kushner H, Li L and Fisher LW: Two members of the SIBLING family of proteins, DSPP and BSP, may predict the transition of oral epithelial dysplasia to ora squamous cell carcinoma. Cancer 116: 1709-1717, 2010.

30. Anunobi CC, Koli K, Saxena G, Banjo AA and Ogbureke KU: Expression of the SIBLINGs and their MMP partners in human benign and malignant prostate neoplasms. Oncotarget 7: 48038-48049, 2016

31. Ogbureke KU, Weinberger PM, Looney SW, Li L and Fisher LW: Expressions of matrix metalloproteinase-9 (MMP-9), dentin sialophosphoprotein (DSPP), and osteopontin (OPN) at histologically negative surgical margins may predict recurrence of oral squamous cell carcinoma. Oncotarget 3: 286-298, 2012.

32. Saxena G, Koli K, de la Garza J and Ogbureke KU: Matrix metalloproteinase 20-dentin sialophosphoprotein interaction in oral cancer. J Dent Res 94: 584-593, 2015.

33. Joshi R, Tawfik A, Edeh N, McCloud V, Looney S, Lewis J, Hsu S and Ogbureke KU: Dentin sialophosphoprotein (DSPP) gene-silencing inhibits key tumorigenic activities in human oral cancer cell line, OSC2. PLoS One 5: e13974, 2010.

34. Gkouveris I, Nikitakis NG, Aseervatham J and Ogbureke KUE: The tumorigenic role of DSPP and its potential regulation of the unfolded protein response and ER stress in oral cancer cells. Int J Oncol 53: 1743-1751, 2018.

35. Murtas D, Maric D, De Giorgi V, Reinboth J, Worschech A, Fetsch P, Filie A, Ascierto ML, Bedognetti D, Liu Q, et al: IRF-1 responsiveness to IFN- $\gamma$ predicts different cancer immune phenotypes. Br J Cancer 109: 76-82, 2013.

36. Ma Z, Qin $\mathrm{H}$ and Benveniste EN: Transcriptional suppression of matrix metalloproteinase-9 gene expression by IFN-gamma and IFN-beta: Critical role of STAT-1alpha. J Immunol 167: 5150-5159, 2001

37. Knüpfer MM, Knüpfer H, Jendrossek V, Van Gool S, Wolff JE and Keller E: Interferon-gamma inhibits growth and migration of A172 human glioblastoma cells. Anticancer Res 21A: 3989-3994, 2001.

38. Cheng SM, Xing B, Li JC, Cheung BK and Lau AS: Interferon-gamma regulation of TNFalpha-induced matrix metalloproteinase 3 expression and migration of human glioma T98G cells. Int J Cancer 121: 1190-1196, 2007.
39. Chawla-Sarkar M, Lindner DJ, Liu YF, Williams BR, Sen GC, Silverman RH and Borden EC: Apoptosis and interferons: Role of interferon-stimulated genes as mediators of apoptosis. Apoptosis 8: 237-249, 2003

40. Yonekura N, Yokota S, Yonekura K, Dehari H, Arata S, Kohama $\mathrm{G}$ and Fujii N: Interferon-gamma downregulates Hsp27 expression and suppresses the negative regulation of cell death in oral squamous cell carcinoma lines. Cell Death Differ 10 313-322, 2003

41. Gadkaree SK, Fu J, Sen R, Korrer MJ, Allen C and Kim YJ: Induction of tumor regression by intratumoral STING agonists combined with anti-programmed death-L1 blocking antibody in a preclinical squamous cell carcinoma model. Head Neck 39 : 1086-1094, 2017

42. Xu B, Shu Y and Liu P: INF- $\gamma$ sensitizes head and neck squamous cell carcinoma cells to chemotherapy-induced apoptosis and necroptosis through up-regulation of Egr-1. Histol Histopathol 29: 1437-1443, 2014

43. Ning Y, Riggins RB, Mulla JE, Chung H, Zwart A and Clarke R: IFNgamma restores breast cancer sensitivity to fulvestrant by regulating STAT1, IFN regulatory factor 1, NF-kappaB, BCL2 family members, and signaling to caspase-dependent apoptosis. Mol Cancer Ther 9: 1274-1285, 2010.

44. Tan H, Zeng C, Xie J, Alghamdi NJ, Song Y, Zhang H, Zhou A and Jin D: Effects of interferons and double-stranded RNA on human prostate cancer cell apoptosis. Oncotarget 6: 39184-39195, 2015.

45. Chen J, Zhao J, Chen L, Dong N, Ying Z, Cai Z, Ji D, Zhang Y, Dong L, Li Y, et al: STAT1 modification improves therapeutic effects of interferons on lung cancer cells. J Transl Med 13: 293, 2015.

46. Liu W, Hu M, Wang Y, Sun B, Guo Y, Xu Z, Li J and Han B: Overexpression of interleukin-18 protein reduces viability and induces apoptosis of tongue squamous cell carcinoma cells by activation of glycogen synthase kinase-3 $\beta$ signaling. Oncol Rep 33: 1049-1056, 2015

47. Dong D, Ni M, Li J, Xiong S, Ye W, Virrey JJ, Mao C, Ye R, Wang M, Pen L, et al: Critical role of the stress chaperone GRP78/BiP in tumor proliferation, survival, and tumor angiogenesis in transgene-induced mammary tumor development. Cancer Res 68: 498-505, 2008

48. Fu Y, Wey S, Wang M, Ye R, Liao CP, Roy-Burman P and Lee AS: Pten null prostate tumorigenesis and AKT activation are blocked by targeted knockout of ER chaperone GRP78/BiP in prostate epithelium. Proc Natl Acad Sci USA 105: 19444-19449, 2008.

49. Daneshmand S, Quek ML, Lin E, Lee C, Cote RJ, Hawes D, Cai J, Groshen S, Lieskovsky G, Skinner DG, et al: Glucose-regulated protein GRP78 is up-regulated in prostate cancer and correlates with recurrence and survival. Hum Pathol 38: 1547-1552, 2007.

50. Cook KL, Shajahan AN, Wärri A, Jin L, Hilakivi-Clarke LA and Clarke R: Glucose-regulated protein 78 controls cross-talk between apoptosis and autophagy to determine antiestrogen responsiveness. Cancer Res 72: 3337-3349, 2012

51. Lee E, Nichols P, Spicer D, Groshen S, Yu MC and Lee AS: GRP78 as a novel predictor of responsiveness to chemotherapy in breast cancer. Cancer Res 66: 7849-7853, 2006.

52. Firczuk M, Gabrysiak M, Barankiewicz J, Domagala A, Nowis D, Kujawa M, Jankowska-Steifer E, Wachowska M, Glodkowska-Mrowka E, Korsak B, et al: GRP78-targeting subtilase cytotoxin sensitizes cancer cells to photodynamic therapy. Cell Death Dis 4: e741, 2013.

53. Zhang J, Jiang Y, Jia Z, Li Q, Gong W, Wang L, Wei D, Yao J, Fang S and Xie K: Association of elevated GRP78 expression with increased lymph node metastasis and poor prognosis in patients with gastric cancer. Clin Exp Metastasis 23: 401-410, 2006

54. Son SM, Byun J, Roh SE, Kim SJ and Mook-Jung I: Reduced IRE1 $\alpha$ mediates apoptotic cell death by disrupting calcium homeostasis via the InsP3 receptor. Cell Death Dis 5: e1188, 2014.

55. Kanekura K, Ma X, Murphy JT, Zhu LJ, Diwan A and Urano F: IRE1 prevents endoplasmic reticulum membrane permeabilization and cell death under pathological conditions. Sci Signal 8: ra62, 2015

56. Fribley AM, Miller JR, Brownell AL, Garshott DM, Zeng Q, Reist TE, Narula N, Cai P, Xi Y, Callaghan MU, et al: Celastrol induces unfolded protein response-dependent cell death in head and neck cancer. Exp Cell Res 330: 412-422, 2015. 
57. Liu X, Lv Z, Zou J, Liu X, Ma J, Wang J, Sa N, Jing P and $\mathrm{Xu}$ W: Afatinib down-regulates MCL-1 expression through the PERK-eIF2 $\alpha$-ATF4 axis and leads to apoptosis in head and neck squamous cell carcinoma. Am J Cancer Res 6: 1708-1719, 2016.

58. Fujimoto A, Kawana K, Taguchi A, Adachi K, Sato M, Nakamura H, Ogishima J, Yoshida M, Inoue T, Nishida H, et al: Inhibition of endoplasmic reticulum (ER) stress sensors sensitizes cancer stem-like cells to ER stress-mediated apoptosis. Oncotarget 7: 51854-51864, 2016.

59. Koumenis C: ER stress, hypoxia tolerance and tumor progression. Curr Mol Med 6: 55-69, 2006

60. Axten JM, Medina JR, Feng Y, Shu A, Romeril SP, Grant SW, Li WH, Heerding DA, Minthorn E, Mencken T, et al: Discovery of 7-methyl-5-(1-\{[3-(trifluoromethyl)phenyl]acetyl $\}-2,3-$ dihydro-1H -indol-5-yl)-7H-pyrrolo[2,3-d]pyrimidin-4-amine (GSK2606414), a potent and selective first-in-class inhibitor of protein kinase $\mathrm{R}$ (PKR)-like endoplasmic reticulum kinase (PERK). J Med Chem 55: 7193-7207, 2012
61. Bobrovnikova-Marjon E, Grigoriadou C, Pytel D, Zhang F, Ye J, Koumenis C, Cavener D and Diehl JA: PERK promotes cancer cell proliferation and tumor growth by limiting oxidative DNA damage. Oncogene 29: 3881-3895, 2010.

62. Vandewynckel YP, Laukens D, Geerts A, Bogaerts E, Paridaens A, Verhelst X, Janssens S, Heindryckx F and Van Vlierberghe H: The paradox of the unfolded protein response in cancer. Anticancer Res 33: 4683-4694, 2013.

63. Lin JH, Li H, Yasumura D, Cohen HR, Zhang C, Panning B, Shokat KM, Lavail MM and Walter P: IRE1 signaling affects cell fate during the unfolded protein response. Science 318: 944-949, 2007.

(i) $(9)$ This work is licensed under a Creative Commons

EY No ND Attribution-NonCommercial-NoDerivatives 4.0 International (CC BY-NC-ND 4.0) License. 